\title{
A 20-year follow-up of men aged 55-64 including coal-miners and foundry workers in Staveley, Derbyshire
}

\author{
A L COCHRANE 1 AND F MOORE 2
}

From Rhoose Farm House, ${ }^{1}$ Rhoose, $S$ Glamorgan, and the MRC Epidemiology Unit, ${ }^{2}$ Cardiff, UK

\begin{abstract}
A survey carried out in 1957 by the Medical Research Council's Pneumoconiosis Unit was based on a private census, with brief industrial histories of men aged 55-64 and 25-34. Four groups were established in this way-"non-dusty," "pure coal-mining," "pure foundry," and "other and mixed." In the 55-64 age group all 387 men have been followed up except for one man, about whom we have no information, and another man, for whom we know the date of death but not the certified cause. The mortality from all causes is similar in all four groups, but there is a slight suggestion of a past or present dust problem, or both, in the foundry population. It is suggested that Staveley is, so far, the best area we have found for studying simple pneumoconiosis of coal-miners. If this suggestion is accepted the mortality rates for miners and ex-miners with simple pneumoconiosis seem similar to those of the same age not exposed to industrial dusts, living in the same area, with similar smoking habits.
\end{abstract}

In the original survey carried out in 1957 by the MRC's Pneumoconiosis Unit ${ }^{1}$ a complete private census, together with brief industrial histories, was taken of men aged 25-34 and 55-64 in Staveley, Derbyshire. On the basis of the industrial histories the population was divided into four groups-_"nondusty," "pure coal-mining," "pure foundry," and "other and mixed." Different sampling fractions were then applied to the four groups. The population was followed up nine years later. ${ }^{2}$ The present paper is concerned with the 20-year follow-up of the group aged 55-64.

\section{Material and methods}

Of the 387 men seen in 1957, we have failed to trace one man, while for another we know the date of death but have not been able to obtain the certified cause of death. The error introduced is thus small. We are confident that the fate of all the others is known, with the certified causes of the deaths, exactly 20 years (to the day) since they were examined. In addition to the causes of deaths, we have used the $x$-ray readings for pneumoconiosis by one

This work was supported in part by a grant from the National Coal Board.

Received 25 June 1979

Accepted 2 October 1979 of us (ALC) and the smoking histories from the time of the first survey in 1957.

\section{Results}

Table 1 gives the mortality from all causes for the four occupational groups. The differences are small and not statistically significant, but it is of interest that the rate for the coal-mining group is lower than that for the non-dusty group. Table 2 gives the specific causes of death according to the "B list" of the International Classification of Diseases (eighth revision). The non-dusty group appears to have a somewhat higher death rate from ischaemic heart disease but a similar mortality rate for respiratory disease to that of the coal-mining group. Table 3 shows the smoking habits of the four groups. As well

Table 1 Staveley men aged 55-64: mortality rates from all causes (strict 20 years)

\begin{tabular}{lrcl}
\hline Group & No & Dead & $\%$ \\
\hline Non-dusty* & 80 & 57 & $71 \cdot 3$ \\
Pure coal-mining & 149 & 98 & $65 \cdot 8$ \\
Pure foundry & 65 & 46 & $70 \cdot 8$ \\
Other and mixed & 92 & 66 & $71 \cdot 7$ \\
All & 386 & 267 & $69 \cdot 2$ \\
\hline *One man untraced has been excluded.
\end{tabular}


Table 2 Staveley men aged 55-64: specific mortality rates (strict 20 years)

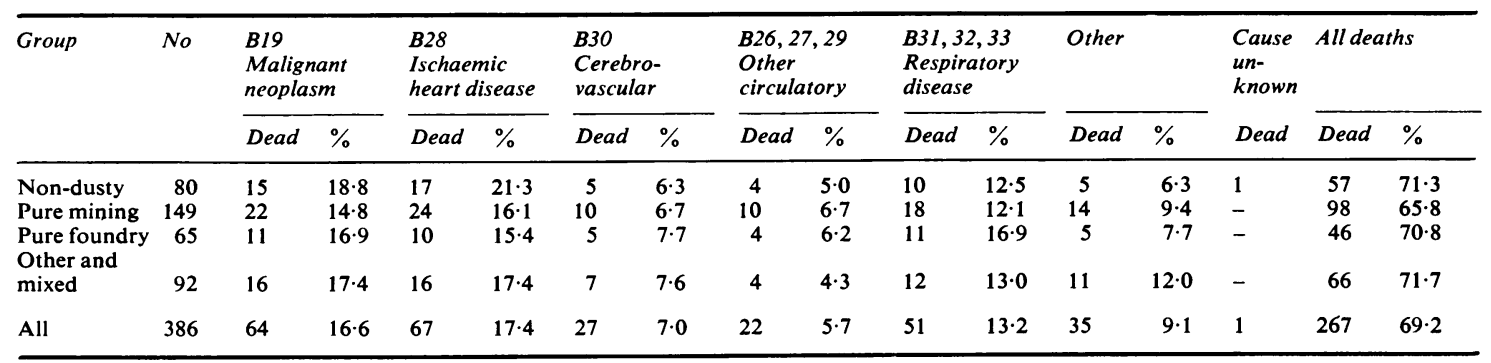

Table 3 Staveley men aged 55-64: smoking habits and mortality

\begin{tabular}{|c|c|c|c|c|c|c|c|c|c|c|c|c|c|c|c|}
\hline \multirow[t]{3}{*}{ Smoking habit } & \multicolumn{15}{|c|}{ Occupation groups } \\
\hline & \multicolumn{3}{|c|}{ Non-dusty } & \multicolumn{3}{|c|}{ Pure mining } & \multicolumn{3}{|c|}{ Pure foundry } & \multicolumn{3}{|c|}{ Other and mixed } & \multicolumn{3}{|c|}{ All four } \\
\hline & No & $\%$ & Dead & No & $\%$ & Dead & No & $\%$ & Dead & No & $\%$ & Dead & No & Dead & $\%$ \\
\hline \multicolumn{16}{|c|}{ Never smoked and } \\
\hline ex-smokers & 24 & $30 \cdot 0$ & 9 & 36 & $24 \cdot 2$ & 18 & 13 & $20 \cdot 0$ & 5 & 18 & $19 \cdot 6$ & 12 & 91 & 44 & $48 \cdot 4$ \\
\hline Pipe only & 13 & $16 \cdot 3$ & 11 & 19 & $12 \cdot 8$ & 13 & 10 & $15 \cdot 4$ & 8 & 21 & $22 \cdot 8$ & 16 & 63 & 48 & $76 \cdot 2$ \\
\hline $1-14$ a day & 19 & $23 \cdot 8$ & 19 & 58 & $38 \cdot 9$ & 38 & 19 & $29 \cdot 2$ & 13 & 28 & $30 \cdot 4$ & 19 & 124 & 89 & $71 \cdot 8$ \\
\hline$\geqslant 15$ a day & 24 & $30 \cdot 0$ & 18 & 36 & $24 \cdot 2$ & 29 & 23 & $35 \cdot 4$ & 20 & 25 & $27 \cdot 2$ & 19 & 108 & 86 & $79 \cdot 6$ \\
\hline All & 80 & $100 \cdot 1$ & 57 & 149 & $100 \cdot 1$ & 98 & 65 & $100 \cdot 0$ & 46 & 92 & $100 \cdot 0$ & 66 & 386 & 267 & $69 \cdot 2$ \\
\hline
\end{tabular}

as underlining the increased mortality associated with smoking, it makes the low mortality of the coalmining group, in comparison with that of the nondusty group, more striking as the former has a slightly lower percentage of non-smokers and ex-smokers.

In the report on the first survey ${ }^{1}$ attention was drawn to the high prevalence of respiratory symptoms and low mean indirect maximum breathing capacity (IMBC) of three subgroups in the other and mixed group - chemical workers, coke-oven workers, and furnacemen. These were not pure groups, the classification being based on "predominant" occupation. Table 4 shows the mortality rates from all causes for the three subgroups. Only the mortality of the coke-oven workers arouses suspicion, but the numbers are too small to enable any valid conclusion to be drawn.

Table 5 compares the Staveley non-dusty and pure mining groups with the corresponding groups in Leigh, ${ }^{3}$ and the Rhondda Fach. ${ }^{4}$ The Staveley

Table 4 Mortality rates for all causes for three industrial subgroups of the other and mixed group

\begin{tabular}{llll}
\hline Subgroup & No & Deaths & $\%$ \\
\hline Chemical workers & 29 & 21 & $72 \cdot 4$ \\
Coke oven workers & 14 & 11 & $78 \cdot 6$ \\
Furnacemen & 18 & 12 & $66 \cdot 7$ \\
\hline
\end{tabular}

results are similar to those in Leigh but very different from those in the Rhondda Fach. The rate for the Staveley mining group is similar to that for the nondusty in the Rhondda, whose standardised mortality ratio was $98 \cdot 7 . .^{4}$ Interestingly the ranking order of the mortality rates for categories $0,1,2$, and 3 is the same as the prevalence of progressive massive fibrosis (PMF) in the three communities $(23 \cdot 1,4 \cdot 7$, $0.0)$.

Table 6 shows the breakdown of the pure mining and pure foundry groups by $x$-ray category of pneumoconiosis. Both show a higher mortality for simple pneumoconiosis. The number of cases in the foundry group is small and the difference is not statistically significant, but it does suggest that there may have been or possibly still is a dust problem in the industry. The difference in the mining group is also not statistically significant, but it is of interest to examine the differences in greater detail (tables 7 and 8 ), which strongly suggest that the difference is due to higher cancer and ischaemic heart disease mortality rates, perhaps due to the higher percentage of cigarette-smoking miners and ex-miners with categories 1, 2, and 3 compared with those with category 0 .

\section{Discussion}

Apart from a slight suspicion about the foundry industry, the fact that the mortality rates of all those 
Table 5 20-year follow-up studies of men aged 55-64 in three mining communities

\begin{tabular}{|c|c|c|c|c|c|c|c|c|c|}
\hline \multirow[t]{2}{*}{ Group } & \multicolumn{3}{|c|}{ Staveley $(1957-77)$} & \multicolumn{3}{|c|}{ Leigh (1954-74) } & \multicolumn{3}{|c|}{ Rhondda Fach (1950-70) } \\
\hline & No & Dead & $\%$ & No & Dead & $\%$ & No & Dead & $\%$ \\
\hline $\begin{array}{l}\text { Non-dusty } \\
\text { Pure miners and ex-miners }\end{array}$ & 80 & 57 & $71 \cdot 3$ & 49 & 33 & $67 \cdot 3$ & 147 & 98 & $66 \cdot 7$ \\
\hline Categories $0,1,2,3$ & 149 & 98 & $65 \cdot 8$ & 81 & 55 & $67 \cdot 9$ & 879 & 667 & $75 \cdot 9$ \\
\hline
\end{tabular}

Table 6 Mortality rates in pure coal-mining and pure foundry groups by category of pneumoconiosis

\begin{tabular}{|c|c|c|c|c|c|c|}
\hline \multirow[t]{2}{*}{ Category of pneumoconiosis } & \multicolumn{3}{|c|}{ Pure coal-mining } & \multicolumn{3}{|c|}{ Pure foundry } \\
\hline & No & Dead & $\%$ & No & Dead & $\%$ \\
\hline $\begin{array}{l}0 \\
1 \\
2 \\
3 \\
\text { ABC }\end{array}$ & $\begin{array}{r}96 \\
27 \\
22 \\
4 \\
0\end{array}$ & $\left.\begin{array}{l}61 \\
21 \\
13 \\
3\end{array}\right\}$ & $\begin{array}{r}63 \cdot 5 \\
69 \cdot 8\end{array}$ & $\begin{array}{c}50 \\
11 \\
2 \\
1 \\
1\end{array}$ & $\left.\begin{array}{c}33 \\
9 \\
2 \\
1 \\
1\end{array}\right\}$ & $\begin{array}{r}66 \cdot 0 \\
85 \cdot 7 \\
100 \cdot 0\end{array}$ \\
\hline All & 149 & 98 & $65 \cdot 8$ & 65 & 46 & $70 \cdot 8$ \\
\hline
\end{tabular}

Table 7 Staveley pure coal-mining group aged 55-64: specific causes of death by category of pneumoconiosis

\begin{tabular}{|c|c|c|c|c|c|c|c|c|c|c|c|c|c|c|c|}
\hline \multirow[t]{2}{*}{$\begin{array}{l}\text { Category of } \\
\text { pneumoconiosis }\end{array}$} & \multirow[t]{2}{*}{ No } & \multicolumn{2}{|c|}{$\begin{array}{l}\text { B19 } \\
\text { Malignant } \\
\text { neoplasm }\end{array}$} & \multicolumn{2}{|c|}{$\begin{array}{l}\text { B28 } \\
\text { Ischaemic } \\
\text { heart disease }\end{array}$} & \multicolumn{2}{|c|}{$\begin{array}{l}\text { B30 } \\
\text { Cerebro- } \\
\text { vascular }\end{array}$} & \multicolumn{2}{|c|}{$\begin{array}{l}\text { B26, 27, } 29 \\
\text { Other } \\
\text { circulatory }\end{array}$} & \multicolumn{2}{|c|}{$\begin{array}{l}\text { 010, } 515 \\
\text { Pneumo- } \\
\text { coniosis }\end{array}$} & \multicolumn{2}{|c|}{$\begin{array}{l}\text { B31, } 32,33 \\
\text { Respiratory } \\
\text { disease }\end{array}$} & \multicolumn{2}{|c|}{ Other causes } \\
\hline & & Dead & $\%$ & Dead & $\%$ & Dead & $\%$ & Dead & $\%$ & Dead & $\%$ & Dead & $\%$ & Dead & $\%$ \\
\hline $\begin{array}{l}0 \\
1,2,3\end{array}$ & $\begin{array}{l}96 \\
53\end{array}$ & $\begin{array}{l}11 \\
11\end{array}$ & $\begin{array}{l}11 \cdot 5 \\
20 \cdot 8\end{array}$ & $\begin{array}{l}14 \\
10\end{array}$ & $\begin{array}{l}14 \cdot 6 \\
18 \cdot 9\end{array}$ & $\begin{array}{l}7 \\
3\end{array}$ & $\begin{array}{l}7 \cdot 3 \\
5 \cdot 7\end{array}$ & $\begin{array}{l}7 \\
3\end{array}$ & $\begin{array}{l}7 \cdot 3 \\
5 \cdot 7\end{array}$ & - & & $\begin{array}{r}13 \\
5\end{array}$ & $\begin{array}{r}13 \cdot 5 \\
9 \cdot 4\end{array}$ & $\begin{array}{l}9 \\
5\end{array}$ & $\begin{array}{l}9 \cdot 4 \\
9 \cdot 4\end{array}$ \\
\hline All & 149 & 22 & $14 \cdot 8$ & 24 & $16 \cdot 1$ & 10 & 6.7 & 10 & $6 \cdot 7$ & - & & 18 & $12 \cdot 1$ & 14 & $9 \cdot 4$ \\
\hline
\end{tabular}

Table 8 Staveley pure coal-mining group aged 55-64: smoking habits and mortality

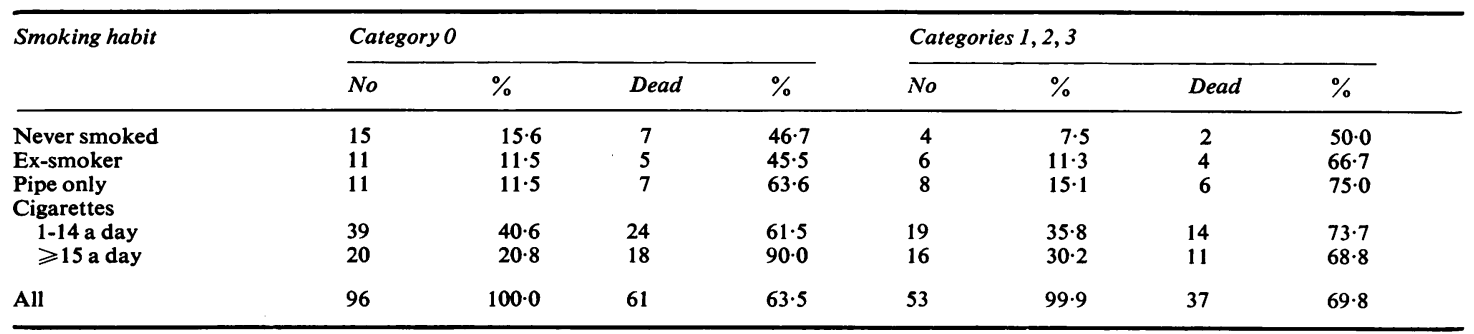

exposed to possibly dangerous dusts in industry in this area are similar to the rate for the non-dusty group, is reassuring. The general - result must be considered satisfactory.

The chief interest lies in the light the results throw on the effect of exposure to coal-dust in general and the long-term effect of simple pneumoconiosis of coal-miners in particular.

Research into disability associated with pneumoconiosis categories $0,1,2$, and 3 has suffered a great deal from a lack of appreciation of the importance of population selection, although the MRC called attention to it as early as $1956^{5}$ and has since studied random samples of miners and ex-miners to reduce the effect of selection. The Rhondda Fach population was excellent for the study of PMF but unsuitable for the study of simple pneumoconiosis as the attacks of PMF were always selecting men out of that population in an unknown way. There was also the unsolved problem of selective migration.

Other problems may arise if miners and ex-miners from different areas are used as one population for a study, owing to the different values for pulmonary function in different areas for the same age/category groups-for instance, the Rhondda Fach and Staveley. ${ }^{6}$ 
Clearly if simple pneumoconiosis is to be studied in a situation as free as possible from selection it should be in one area with little or no PMF and little migration. Staveley meets both criteria. There was no PMF in our "mining" sample, and there is evidence of a relatively low migration rate. ${ }^{6}$ Then when we look at the $0,1,2$, and 3 group in Staveley we find an overall mortality rate lower than the nondusty group and a probable SMR of about 100 , an IMBC of 87 compared with 90 for the non-dusty group, ${ }^{1}$ and respiratory death rates are practically identical in the two groups. It is true that there was a slightly higher prevalence of cough, sputum, and breathlessness in the $0,1,2$, and 3 group, ${ }^{1}$ but this can be reasonably explained by the higher prevalence of smoking (table 3 ).

Turning now to the differences between category 0 and categories 1,2 , and 3 , the mortality rates of the latter are a little, but not significantly, higher, which is perhaps explained by the higher prevalence of cigarette smokers. Those with simple pneumoconiosis had similar IMBC's (87) to those with category 0 (also 87$)^{1}$; the somewhat slightly higher prevalence of respiratory symptoms ${ }^{1}$ are reasonably explained by the higher prevalence of smokers (table 8 ).
We think that this is the true picture of simple pneumoconiosis and in it we find little support for the existence of chronic bronchitis and emphysema induced by coal-dust, however defined.

\section{References}

${ }^{1}$ Higgins ITT, Cochrane AL, Gilson JC, Wood CH. Population studies of chronic respiratory disease. A comparison of miners, foundry workers, and others in Staveley, Derbyshire. Br J Ind Med 1959;16:255-68.

${ }^{2}$ Higgins ITT, Gilson JC, Ferris BG Jr, Waters WE, Campbell H, Higgins MW. Environmental epidemiology. IV Chronic respiratory disease in an industrial town; a nine-year follow-up study. Preliminary report. Am J Public Health 1968;58:1667-76.

${ }^{3}$ Cochrane AL, Moore F. Preliminary results of a 20-year follow-up of a random sample in an industrial town. $B r$ Med J 1978; ; :411-2.

4 Cochrane AL, Haley TJL, Moore F, Hole D. The mortality of men in the Rhondda Fach 1950-1970. Br J Ind Med 1979;36:15-22.

${ }^{5}$ Carpenter RG, Cochrane AL, Gilson JC, Higgins ITT. The relationship between ventilatory capacity and simple pneumoconiosis in coalworkers. The effect of population selection. Br J Ind Med 1956;13:166-76.

- Cochrane AL, Higgins ITT, Thomas J. Pulmonary ventilatory functions of coalminers in various areas in relation to the x-ray category of pneumoconiosis. $\mathrm{Br} J$ Prev Soc Med 1961;15:1-11. 